\title{
ANÁLISE DO TEOR DE FLÚOR NAS ÁGUAS DE ABASTECIMENTO PÜBLICO
}

\author{
Jose Wives Filho* \\ Eduardo Roberto Corrêa de Barros** \\ Flávio Belan dos Santos ***
}

WIVES Fọ, José et alii. Análise do teor de flúor nas águas de abastecimento público. Revista da Faculdade de Odontologia, Porto Alegre, 21-22-23-24:

$9-20,1979 / 82$.

Descritores: FLÚOR, ÁGUAS DE ABASTECIMENTO PÚBLICO

\section{RESUMO}

Há controvérsias sobre se um determinado teor de flúor se mantém nos niveis esperados em qualquer ponto de uma rede de abastecimento público de água.

No presente estudo, os Autores procuraram verificar a ocorrência ou não de tais variações, utilizando-se da Estação de Tratamento de Água de Belém Novo, Porto Alegre.

Durante 15 dias, analisaram 450 amostras de água fluorada, levantadas em seis diferentes pontos das localidades de Vila Restinga e Vila Nova Restinga, variando os horários. Comparam os teores médios diários obtidos com os teores médios computa- dos pela Estação em um ponto situa. do à saída do reservatório subterrâneo, não encontrando diferenças estatisticamente significantes.

\section{INTRODUÇÃO}

A cárie dentária é o problema de saúde mais importante da Odontologia. Com sua prevalência atingindo cerca de $98 \%$ da população mundial, persiste, ainda, como um problema de Saúde Pública de graves proporções. Transfórmá-la, pois, num típico "problema social de saúde públi$\mathrm{ca}^{\prime \prime 18}$, deve ser meta prioritária do dentista-sanitarista.

Entretanto, principalmente nas últimas três décadas, assinalaram-se,

\footnotetext{
* Mestre em Odontologia. Professor Assistente da Disciplina de Odontologia Social e Preventiva da Faculdade de Odontologia da Universidade Federal de Pelotas, RS.

**Mestre em Odontologia. Professor Assistente do Departamento de Odontologia Preventiva e Social da U.F.R.G.S.

***Docente-Livre. Professor Titular da Disciplina de Odontologia Social e Preventiva da Faculdade de Odontologia da Universidade Federal de Pelotas, RS.
} 
de maneira decisiva, dois grandes marcos que vieram transformar completamente as atividades da Odontologia relacionadas com a Saúde Pública e que the permitiram passar do aspecto puramente curativo a uma fase enfática nos procedimentos preventivos primários.

O primeiro desses marcos constituiu-se na descoberta de métodos aplicáveis em larga escala na prevenção parcial'da cárie dentária, representado pelas descobertas no dominio dos empregos do flúor em Odontologia. O segundo, pela utilização e divulgação de uma maneira simples, prática e uniforme de medir quantitativamente essa enfermidade, através do índice CPOD.

Segundo KEYES7, a utilização do flúor nas águas de abastecimento público, por si só, não resolverá todos os problemas de incidência de cárie, pois, além de ser parcial a proteção, o agente responsável por essa enfermi. dade não é inibido.

Particularizando-se o Rio Grande do Sul - Estado pioneiro no Brasil a promulgar uma lei, nos idos de 1957. obrigando seus municípios a flunrarem as águas de abastecimento público - vê-se que a implantação dessa medida ainda deixa a desejar, pois, de 232 municípios, somente 99 contam com a fluoração das águas de abastecimento público ${ }^{19}$. Legislação Federal, neste sentido, deveria ter, na prática, forçado o aparecimento maciço de municípios com suas águas fluoradas; mas, pelo que se sabe, a realidade é bem outra.

O município de Porto Alegre, R.S. - cujo teor de flúor determinado pela CORSAN é de 0,80 ppm para os meses de novembro a abril, e de 1,0 ppm para os meses de maio a outubro ${ }^{14}$ - vale-se, para a fluoração das águas de abastecimento público, de equipamento dosador notavelmente simples, de custo e manutenção não onerosos e de fácil manejo.

Todavia, não só a aplicação de flúor nas águas é necessária: é preciso, "também, que nos asseguremos de que a população esteja recebendo o elemento adicionado em quantidade adequada.

A literatura informa que o flúor, adicionado à água de abastecimento, não se desprende nem é absorvido, permanecendo estável a quantidade adicionada à rede de distribuição, até a sua posterior utilização pelo organismo humano.

MAIER ${ }^{12 ; 13}$ relata que poderão ocorrer erros no teor de flúor na rede de abastecimento, provenientes, dentre outras, das seguintes causas: a) absorção de íons de flúor no recobrimento interno dos canos principais, b) diluição da água fluorada com a não fluorada e c) funcionamento inadequado do sistema de abastecimento. Aconselha, ainda, a serem feitos programas de amostragem em diferentes pontos da rede, a fim de se detectarem possíveis imper. feições do dosador ou decorrentes das operações efetuadas pelos recursos humanos da Estação.

A pesquisa se baseou numa informática original.

Formularam-se hipóteses que visaram verificar, a um nível de $5 \%$, se existe ou não variação estatisticamente significante entre os teores médios de flúor detectados em diferentes pontos da rede de abastecimento público de água e os teores originalmente dosados.

Com a finalidade de testar as hipóteses, os seguintes objetivos foram estabelecidos: 
1) Comparar os teores médios de flúor dos seis pontos analisados, em conjunto, com os teores médios de flúor do ponto localizado à saída da Estação e por ela computado;

2) determinar se a análise dos teores médios de flúor, levantados de um único ponto, apresenta um grau de confiança capaz de representar o teor de flúor existente em qualquer ponto da rede;

3) comparar os teores médios de flúor detectados à saída da Estação com os teores médios de flúor obtidos nesse mesmo ponto pela própria Estação.

\section{REVISÃO DA LITERATURA}

Revisando a literatura pertinente, encontram-se autores que não admitem que ocorra variação do teor de flúor em diferentes pontos da rede de abastecimento d'água, como PERA ${ }^{16}$, que, referindo-se ao problema, afirma que o flúor adicionado à água de abastecimento público é estável, isto é, permanece presente até a sua utilização pelo organismo humano.

Também o Manual do DMAE17, de Porto Alegre, afirma que a água não tem demanda de flúor, como sucede com o cloro. Que o flúor não se desprende nem é absorvido, que a quantidade adicionada mantém-se estável na rede de distribuição. Portanto, não admite que haja variação do teor de flúor em diferentes pontos da rede de abastecimento público.

MAIER 10 diz que "'não se conhe$œ$ reações entre o flúor na água e compostos formados, após a etapa de cloração, a uma concentração de 1,0 ppm de flúor".

HARRIS6, referindo-se às fases mecânicas da fluoração das águas em
Grand Rapids, que acompanhou por mais de 10 anos, afirmou que, "durante todo esse tempo pudemos constantemente controlar o teor de flúor em qualquer ponto das canalizações em suas extremidades, constatando ser a dosagem a mesma e igual àquela aplicada".

MACHADO 8 relata que os resultados de operações práticas e experimentações indicam que, "quando a dosagem de fluoreto é feita numa concentração desejada, na Estação de Tratamento de Água, o mesmo nível do teor de fluoreto é uniforme e mantém-se através de todo o Sistema de Tratamento de Água".

Também SUFELT22 cita que os resultados de análise e comparação de teores de flúor de diferentes pontos da rede de abastecimento e o teor de flúor assinalado na saída da Estação revelam-se perfeitamente uniformes.

EULER5, corroborando as constatações de outros autores, mostrou que "o consumidor recebe o fluoreto como dosado na água em teor ideal em que qualquer ponto residencial abastecido pela rede".

Por sua vez, MAIER 12 ainda relata que "contrariamente ao que pensam alguns críticos da fluoretação, os tubérculos que se formam no interior das tubulações, principais que acumulam flúor, não se dissolvem ou se soltam repentinamento, o que aumentaria o nível de fluoretos na água. Como as crostas se aderem muito fortemente, é necessário uma raspagem muito vigorosa para removê-los. Por isso se acredita que não seriam removidos por um fluxo turbulento de água".

Por outro lado, há autores que admitem a ocorrência de variação do 
teor de flúor em diferentes pontos da rede de abastecimento de água.

CORDERO3 afirmou que o sulfato de alumínio, quando empregado em altas doses, nas Estações de Tratamento, é um eficaz removedor de flúor, podendo, pois, ser utilizado para retirar possíveis excessos de flúor existente na água, já que ele seria removido pela formação de um fluoreto de alumínio complexo e pela adsorção dos flocos formados.

As Estações de Tratamento, que aplicam o flúor junto ao sulfato de alumínio ocasionam, assim, um grande desperdício do sal, e, a menos que corrijam o teor, o mesmo estará aquém do desejado.

MAIER 9,10 diz que programas de amostragem em diferentes pontos da rede devem ser feitos a fim de se detectarem imperfeições do sistema ali. mentador (no caso os dosadores de flúor) e perdas do flúor no sistema de abastecimento. Afirma ainda que erros no teor de flúor se registrarão em diferentes pontos do sistema se ele se mantém ou opera de forma que não contribua a seu funcionamento ótimo 13 .

TEIXEIRA23, em um estudo com fluorita na cidade de Farroupilha (RS), encontrou alguns problemas durante a aplicação do processo, como o que ocorre quando se processa a pos-alcalinização, com uso da água de cal, afirmando que, "Freqüentemente, os teores de flúor, nas águas tratadas (do reservatório de acumulação) e da rede de acumulação) e da rede de distribuição são levemente superiores ao da água coagulada".

SPITZ e colaboradores 20 , a fim de verificar se o teor de flúor estava sendo mantido constante, realizou estudos em três cidades americanas, de 1945 a 1954, e encontrou variação que estava dentro do esperado (média de 1,07 pp, e desvio padrão de 0.06).

Em 1971, um estudo sobre o nível de flúor nas águas de abastecimento de. 119 Sistemas de Abastecimento em Tenessee, mostrou que apenas $50 \%$ desses Sistemas estavam com os níveis dentro do esperado para a região (entre 0,7 e 1,2 ppm)2.

Sendo a fluoração, antes mencionnada, uma das medidas mais eficientes e eficazes para a redução do problema cárie dentária, é necessário assegurar-se de que, em cada torneira da população abastecida, esteja fluindo água com um teor ótimo, aquele que, se espera, dê o benefício proposto pela medida. Pelo exposto, parece não ser ponto pacífico a existência ou não de variações do teor de flúor na rede de abastecimento, já que, na prática, muitos fatores podem influir para que elas ocorram.

\section{MATERIAIS E MÉTODOS}

\subsection{Dados e Informações}

Foram tomadas amostras de água fluorada da rede de abastecimento da Estação de Tratamento da Água de Belém Novo, Porto Alegre, R.S., em diferentes pontos, horários e dias do mês de março de 1977.

A fim de evitar-se a possível interferência de fatores em potencial, não previsíveis, que pudessem causar variações outras no teor de flúor, distintas daquelas objeto deste estudo, optou-se por uma Estação de Tratamento cuja rede de abastecimento não se conectasse com nenhuma outra.

A Estação de Belém Novo - cuja rede totaliza $83.950 \mathrm{~m}$ - está situada 
a 1 quilômetro da margem esquerda do rio Gauíba, de onde retira a água para o tratamento. Possui uma capa. cidade média de $5.514 \mathrm{~m}^{3}$ de água tratada por die, abastecendo es comunidades de Belém Novo, Vila Restinga, Vila Nova Restinga, Ponta Grossa, Leblon E Bda Vista

A porcáo da rede selecionada fo a que se dirige as localidades de Vila Restinga e Vila Nova Restinga. Esta porcäo beneficia cerca de 15 mil pessoas e possui dois encanamentos, dispostos lado a lado, de 150 e de $200 \mathrm{~mm}$, respectivamente, que forne$œ m$ água para essas localidades. Desce a Estação de Tratamento até o reservatório terminal, o trajeto percorrido pela rede é de pouco mais de 9 quilômetros, excluindo-se as ramificações existentes.

O mecanismo dosador de flúor empregado consta de um equipamento simplificado desenvolvido pela CORSAN, chamado de "cone de dosagem" ou "cone de dissolução"1 O sal de flúor utilizado é fluorsilicato de sódio.

\section{Experiência Piloto}

Foi realizada uma experiência piloto que deu condições a que se pudesse:

1) obter a aceitação da pesquisa pela comunidade e pelos técnicos da Estação, já que se necessitaria da sua colaboração em determinadas ocasiões, como, por exemplo, permitir a coleta de água na residência, preparar o laboratório para a realização das análises;

2) ajustar critérios e procedimentos relacionados à coleta e análise das amostras ;

3) estabelecer o tempo mínimo necessário para percorrer a rede ;
4) eliminar, dentre todos os pontos previamente considerados como favoráveis para a realização do levantamento, aqueles que não apresentassem possibilidades mais seguras de retirar as amostras em qualquer hora do dia ou em qualquer dia do desenvolvimento da pesquisa;

5) determinar a duração, em dias, da experiência propriamente dita, a quantidade de pontos a serem pesquisados, bem como o número de amostras de cada ponto, todos considerados em seu mínimo;

6) padronizar "a posteriori" os procedimentos de coleta e de análise dos dados manipulados.

A experiência piloto foi desenvolvida em três fases, que se distinguiram uma das outras pelas distâncias em relação à Estação e pelos diferentes pontos pesquisados, tendo em vista os propósitos acima referidos. Foi realizada em diferentes horários do dia a fim de captar as alterações do consumo d'água que ocorrem durante o dia e possíveis alterações do teor de flúor nesses horários e nas distâncias consideradas. Em cada fase tomou-se cinco pontos do trajeto. A primeira abrangeu os três primeiros quilômetros da rede, a segunda realizou-se no trajeto compreendido entre o terceiro e o sexto quilômetro e a terceïra fase, ,do sexto ao nono quilômetro.

A análise dos teores de flúor neste teste piloto mostrou uma variação para o teor padrão, que, submetidos ao tratamento estatístico das diferenças das medias, apresentou significância ao nível de $5 \%$. Segundo os técni$\cos$ da Estação, cientificados do fato, isto se explicava porque, nesse período, houve uma ruptura da rede, falta de energia elétrica com diversas inter. 
rupções no fornecimento de água, que produziu as alterações quando se retomava o fornecimento.

\subsection{População Estudada}

Experiência propriamente dita

A experiência propriamente dita foi realizada levando-se em conta todos os ensinamentos colhidos na experiência piloto, constituindo-se, portanto, numa pesquisa inteiramente nova.

Foram utilizadas 450 amostras de água fluorada provenientes da Estação de Tratamento de Belém Novo, da porção da rede que se dirige às localidades de Vila Restinga e Vila Nova Restinga, abrangendo uma extensão de 9 quilômetros. Fize. ram-se tomadas em seis diferentes pontos dessa porção.

A localização dos seis pontos analisados, conforme a determinação da experiência piloto, são os seguintes:

ponto A - localizado na saída do reservatório subterrâneo da Estação de Tratamento;

ponto B - localizado a aproximadamente 3 quilômetros da Estação de Tratamento;

ponto C - localizado a aproximadamente 6 quilômetros da Estação de Tratamento;

ponto $D$ - localizado a aproximadamente 8 quilômetros da Estação de Tratamento;

ponto $E$ - localizado a aproximadamente 8 quilômetros e meio da Estação de Tratamento;

ponto $F$ - localizado a aproximadamente 9 quilômetros da Estação de Tratamento.
Diariamente, em cada um dos se is pontos, e durante 15 dias ininterruptos, foram coletadas cinco amostras de água, totalizando o conjunto de 450. Como expressão paramétrica diária de cada ponto, calculou-se a respectiva média aritmética. Obtiveram-se, assim, os teores médios diários de flúor em cada ponto, correspondentes aos horários e períodos de tempo discriminados; os teores médios diários de flúor dos seis pontos, em conjunto, que se denominou de $N$; a média global dos quinze dias para cada ponto e uma média global de $N$, nos 15 dias. Vide tabela nọ 1.

Tais médias se constituíram nos dados elementares de análise, juntamente com o teor médio de flúor oriundo de cinco tomadas efetuadas à saída do reservatório subterrâneo da Estação de Tratamento num único ponto - que coincide com nosso ponto $A$ - nos mesmos dias e horários, provenientes de 75 informações retiradas das planilhas da Estação de Tratamento. Este será denominado, daqui por diante, de $A^{\prime}$, sempre que a referência seja feita a dados coletados pela própria Estação. Este ponto serviu como termo de comparação com os dados levantados.

\subsection{Procedimentos de Levantamento}

Foram utilizados 30 frascos de polietileno com tampa com capacidade de $500 \mathrm{ml}$. A utilização desse tipo de frasco teve em vista evitar possível reação do flúor com as suas paredes, embora o tempo de permanência tenha sido pequeno (no máximo 5 horas).

O volume adotado teve por finalidade ter-se apreciável quantidade da amostra para possiveis repetições de medição. 
Tais frascos foram reutilizados por 15 vezes, sendo recuperados para uso através de lavagem com água destilada e postos a secar durante a noite.

O levantamento foi feito nos horários: $7 \mathrm{~h}, 10 \mathrm{~h}, 13 \mathrm{~h}, 16 \mathrm{~h}, 19 \mathrm{~h}$.

Nos horários estabelecidos, partiase da Estação, percorrendo os pontos referidos em um tempo máximo de 30 minutos. Em cada ponto da rede, determinado para a coleta, procediase da seguinte maneira:

19) recolhia-se a amostra de água no frasco apropriado

2 .) acondicionava-se o frasco para transporte após a sua identificaça

30) anotava-se na ficha diária o ponto e hora da coleta.

\subsection{Método de Coleta de Dados}

Terminada cada uma das coletas das amostras, eram, no laboratório da Estação de Tratamento de Agua, iniciadas as análises do teor de flúor nelas contido. O método selecionado para essa análise foi o Método de Elétrodo Especifico15, pela precisão e possibilidade de sua realização na prática21. Foram seguidos rigorosa. mente os passos preconizados para essa técnica, atentando-se, inclusive, para a correção do $\mathrm{pH}$ das amostras, que oscilou entre 5,0 e 5,5.

$\mathrm{O}$ aparelho determinador da attvidade iônica do flúor utilizado*, bem como o material, foram fornecidos rela própria Estação de Tratamento de Água de Belém Novo.

\subsection{Análise dos Dadas}

A análise estatística incidiu, para maior fidelidade das informações numéricas obtidas, em distribuições

\footnotetext{
*pH Fluoride Meter, modelo 12320
}

amostrais de médias dos seis pontos trabalhados e do ponto pesquisado pela Estação, reunindo-se todos os dados obtidos no dia em uma média aritmética para cada ponto pesquisado. Foi empregado o teste Análise de Variância para as comparações globais, o teste de Tukey para as comparações individuais, e o teste de Student, testados ao nível de $5 \%$.

\section{RESULTADOS}

Os resultados descritivos e analíticos são apresentados na tabela no 1.

A tabela-mestra no 1 apresenta todos os dados reunidos com suas respectivas médias diárias de cada ponto, a média de cada ponto nos 15 dias do estudo, a média global dos seis pontos em cada dia e a média global de cada dia do ponto localiza. do à saída da Estação e por ela com. putado, bem como a sua média dos 15 dias. Ainda o desvio padrão dos pontos A, B, C, D, E e F dos 15 dias (s).

Também é apresentado um quadro do teste Análise de Variância aplicado aos resultados, no 1 , um quadro com o teste de Tukey, no 2. 
Tabela n: 1 - Valores médios dos teores de flúor de cinco tomadas diarias dos seis pontos pesquisados durante 15 dias, e as medias diárias de flúor, do ponto localizado na saída do reservatório subterrâneo, pela Estação de Tratamento de Água de Belém Novo, nos mesmos horários e perfodo, 15 a 30 de março de 1977.

\begin{tabular}{|c|c|c|c|c|c|c|c|c|c|c|c|c|c|c|c|c|c|c|}
\hline \multirow{2}{*}{$\begin{array}{c}\text { Pontos } \\
\text { de } \\
\text { Rede }\end{array}$} & \multicolumn{18}{|c|}{ VALOR MÉDIO DIÁRIO DE CINCO AMOSTRAS } \\
\hline & dias & $1 \%$ & 29 & $3 ?^{\circ}$ & $4 ?$ & $5 ?^{\circ}$ & $6 ?$ & 70 & 80 & $9 ?$ & $10^{\circ}$ & 119 & $12{ }^{\circ}$ & $13 ?$ & $14 ?$ & $15 ?$ & $\begin{array}{c}\text { Media } \\
(\bar{x})\end{array}$ & $\mathbf{s}$ \\
\hline A & \multicolumn{2}{|c|}{0,84} & 0,95 & 0,94 & 0,88 & 0,86 & 0,98 & 0,93 & 0,86 & 1,20 & 0,86 & 0,90 & 0,78 & 0,94 & 0,86 & 0,81 & 0,91 & 0,24 \\
\hline B & \multicolumn{2}{|c|}{0,64} & 0,89 & 0,70 & 1,04 & 0,62 & 0,86 & 0,84 & 0,76 & 1,19 & 0,80 & 0,80 & 0,70 & 0,72 & 0,75 & 0,74 & 0,80 & 0,26 \\
\hline C & \multicolumn{2}{|c|}{0,64} & 1,00 & 0,73 & 1,06 & 0,66 & 0,85 & 0,83 & 0,84 & 1,19 & 0,84 & 0,82 & 0,69 & 0,73 & 0,72 & 0,65 & 0,82 & 0,26 \\
\hline$D$ & \multicolumn{2}{|c|}{0,63} & 0,92 & 0,71 & 1,05 & 0,62 & 0,87 & 0,82 & 0,79 & 1,32 & 0,89 & 0,83 & 0,68 & 0,73 & 0,71 & 0,66 & 0,82 & 0,23 \\
\hline$E$ & \multicolumn{2}{|c|}{0,63} & 0,93 & 0,67 & 0,96 & 0,63 & 0,88 & 0,82 & 0,79 & 1,18 & 0,97 & 0,84 & 0,67 & 0,72 & 0,73 & 0,68 & 0,81 & 0,24 \\
\hline$F$ & \multicolumn{2}{|c|}{0,62} & 0,92 & 0,71 & 0,92 & 0,65 & 0,87 & 0,83 & 0,84 & 1,18 & 0,94 & 0,83 & 0,67 & 0,71 & 0,73 & 0,70 & 0,81 & 0,24 \\
\hline $\begin{array}{c}\text { Média } \\
\mathrm{N}\end{array}$ & \multicolumn{2}{|c|}{0,67} & 0,93 & 0,74 & 0,98 & 0,67 & 0,88 & 0,84 & 0,81 & 1,21 & 0,88 & 0,84 & 0,70 & 0,76 & 0,75 & 0,71 & 0,82 & \\
\hline$A^{\prime}$ & \multicolumn{2}{|c|}{0,61} & 0,90 & 0,67 & 0,84 & 0,69 & 0,89 & 0,79 & 0,64 & 1,01 & 0,70 & 0,71 & 0,60 & 0,65 & 0,66 & 0,68 & 0,74 & \\
\hline
\end{tabular}

Quadro nọ 1 - Análise de Variância dos teores médios de flúor obtidos nos pontos A, A', B, C, D, E, F, Estaçâo de Tratamento de Água de Belém Novo, Porto Alegre, 15 a 30 de março de 1977.

\begin{tabular}{l|c|c|c|c}
\hline $\begin{array}{l}\text { Causas da } \\
\text { Variação }\end{array}$ & G.L. & SO & QM & F \\
\hline $\begin{array}{l}\text { Tratamento } \\
\begin{array}{l}\text { Erro } \\
\text { Experimental }\end{array}\end{array}$ & 6 & 0,22 & 0,037 & $1,76^{*}$ \\
\hline & 104 & 2,29 & & \\
\hline
\end{tabular}

F $5 \% 6 ; 98=2,25$

"não significante a $5 \%$

Quadro n! 2 - Teste de Tukey para as comparações individuais entre os pontos A, B, C, D, E, F e A'.

\begin{tabular}{|c|c|c|c|c|c|c|c|c|}
\hline \multicolumn{1}{|c|}{$\begin{array}{c}\text { Diferenças } \\
\text { Pontos }\end{array}$} & $\bar{x} i$ & $\bar{x} i-0,74$ & $\bar{x} i-0,80$ & $\bar{x} i-0,81$ & $\bar{x} i-0,81$ & $\bar{x} i-0,82$ & $\bar{x} i-0,82$ & $\bar{x} i-0,91$ \\
\hline A & 0,91 & $0,17^{*}$ & 0,11 & 0,10 & 0,10 & 0,09 & 0,09 & - \\
\hline C & 0,82 & $0,08^{*}$ & 0,02 & 0,01 & 0,01 & - & - & $-0,09$ \\
\hline D & 0,82 & $0,08^{*}$ & 0,02 & 0,01 & 0,01 & - & - & $-0,09$ \\
\hline E & 0,81 & $0,07^{*}$ & 0,01 & - & - & $-0,01$ & $-0,01$ & $-0,10$ \\
\hline F & 0,81 & $0,07^{*}$ & 0,01 & - & - & $-0,01$ & $-0,01$ & $-0,10$ \\
\hline B & 0,80 & $0,06^{*}$ & - & $-0,01$ & $-0,01$ & $-0,02$ & $-0,02$ & $-0,11$ \\
\hline$A^{\prime}$ & 0,74 & - & $-0,06$ & $-0,07$ & $-0,07$ & $-0,08$ & $-0,08$ & $-0,17$ \\
\hline
\end{tabular}

\section{Q. $5 \times 5 \%=0,3632$}

Q tabela $5 \%=4,54$

"não significante a $5 \%$ 


\section{DISCUSSÃO}

O objetivo 1 teve como intento comparar todos os teores médios de flúor dos seis pontos analisados, em conjunto, com os teores médios do ponto localizado à saída da Estação e por ela computado.

Pela análise de variância (quadro nọ 1) dos dados obtidos, vê-se que não houve significância entre as diferenças observadas, devidas, portanto, somente à magnitude de grandeza das variáveis, evidenciadas através do intervalo de confiança de $95 \%$.

Interpretando este resultado, em seu todo, isto equivale a dizer que o teor de flúor, em qualquer ponto da rede de distribuição da água de abastecimento público, adicionado pela Estação de Tratamento de Água de Belém Novo, é o mesmo, sendo as diferenças apenas aparentes.

Tal resultado foi semelhante ao encontrado por SPITZ20 e colaboradores em estudos realizados em cidades norte-americanas.

Estes resultados também estão de acordo com as observações feitas por HARRIS6, que relata ter podido controlar o teor de flúor em todos os pontos da rede. Ainda confirmam os estudos de MACHADO 8 , SUFELT22 e EULER ${ }^{5}$, relativos à manutenção dos teores de flúor na rede de abastecimento.

Também se pode dizer que as populações de Vila Restinga e Vila Nova Restinga estão recebendo o teor de flúor, distribuído pela Estação, dentro de um nível aproximadamente esperado. Verifica-se, pela tabela n? 1, que, em muitas ocasiões, o teor médio de flúor apresentou-se abaixo de 0,70 ppm, que é o menor valor preconizado por CULP \& STOLTENBERG ${ }^{4}$ para que se desenvolvam dentes fortes e sadios. Isso poderá, portanto, prejudicar os resultados da aplicação da medida à população, se a sua ocorrência se tornar rotineira. Segundo MAIER ${ }^{11}$, para DEAN, à medida que o nível de flúor baixa de 1,0 ppm, a incidência de cárie vai aumentando, até que, ao aproximar-se de zero esse teor, não se registra nenhuma redução de cárie apreciável.

Seria lícito, em vista da concordância das partes com o conjunto, no que tange à não significância dos resultados, dizer que, efetivamente, o flúor adicionado pela Estação de Belém Novo permanece estável em qualquer ponto da rede, o que corrobora PERA ${ }^{16}$, o Manual do DMAE de Porto Alegre 17, MAIER 10 e outros autores.

A observação da média global dos teores de flúor nos 15 dias mostra que eles se mantiveram dentro dos níveis propostos pelo Departamento Municipal de Água e Esgotos para o período do ano considerado.

Com relação ao objetivo 2, pretendeu-se, em última análise, verificar se o teor médio de flúor, levantado rotineiramente por um único ponto, poderia merecer alguma confiança, como representativo de toda a rede. Baseando-se nos resultados obtidos, pelo teste de Tukey, pode dizer-se que foi merecedor de confiança no presente caso. Isto não equivale a dizer, entretanto, que se deva analisar, via-de-regra, um único ponto: a amostra levantada em vários pontos será sempre mais fidedigna, em qualquer caso, e neste ponto secundamos MAIER ${ }^{10}$, dentre outros.

O objetivo 3 pretendeu comparar a média diária de cinco tomadas amostrais, num período de quinze 
dias, no ponto localizado à saída da Estação $(\bar{x} A)$, efetuadas num mesmo local e horários em que rotineiramente a Estação levanta o teor de flúor existente, com os dados médios oficialmente registrados por ela nesses mesmos dias e horários, $\left(\bar{x} A^{\prime}\right)$. Ele mostra que a diferença das médias foi igual a 0,17 , com um intervalo de confiança ao nível de $95 \%$ compreendido entre $0,00|\ldots-. .| 0,$.32 indicando que seu verdadeiro valor está entre estas duas grandeżas. O teste de Student apontou uma significância nas diferenças dos teores de flúor entre os dados coletados e os retirados das planilhas da Estação nos mesmos horários e dias da pesquisa.

Observa-se ainda que a diferença média global entre o ponto $A$ e o $A^{\prime}$ teve o valor 0,17 . Contudo, na práti-ca, esse valor não se traduz em prejuízo para a ação do flúor.

É interessante notar que os valores citados, analisados pelo teste de Tukey, apontaram a não significância entre os resultados.

Todos os três objetivos foram testados ao nível de $5 \%$ de probabilida. des.

\section{CONCLUSÕES}

Em vista da análise e discussão dos resultados, nas condições em que foi desenvolvida a pesquisa, é lícito concluir, ao nivel de 5\%, que, globalmente, não houve variação estatisticamente significante entre os teores médios de flúor detectados em diferentes pontos da rede de abastecimento público de água $\mathrm{e}$ os teores originalmente dosados.

Concomitantemente,

1) não houve diferença estatisticamente significante entre os teores médios de flúor dos seis pontos analisados, em conjunto, com os teores médios de flúor do ponto localizado à saída da Estação e por ela computado;

2) a análise dos teores médios de flúor, levantados de um único ponto, apresentou, no presente estudo, um grau de confiança capaz de representar o teor de flúor existente em qualquer ponto da rede;

3) o teste de Student assinalou diferença estatisticamente significante entre os teores médios de flúor detectados à saída da Estação e os teores médios de flúor obtidos nesse mesmo ponto pela própria Estação.

Contudo, o teste de Tukey não acusou diferença estatisticamente significante entre esses teores médios.

\section{SUMMARY}

There have being some controversies as to whether the fluorine level is maintained, as expected, at any point in a running water supply.

In the present research the Author tried to verify the occurrence or nonoccurrence of such variations through the resort of water treatment of Belém Novo, Porto Alegre, RS.

For 15 days, in different periods of time, the Author analysed 450 samples of fluoridated water in six different points of Vila Restinga and Vila Nova Restinga.

He compared the daily level rate obtained with those computed by the resort at the exit of the underground reservoir.

Thus finding no differences statistically significant. 


\section{REFERÊNCIAS BIBLIOGRÁFICAS}

1. CASTIEL, Víctor. Experiência prática, equipamento simplificado de dosagem de sais de flúor em águas, Rio Grande do Sul, Brasil. In: Organización Mundial de la Salud. Organización Panamericana de la Salud. Se. minário internacional de fluoruración. Washington, D.C., 1977. (Documento $\mathrm{n}$ ? FDH/61).

2. CONCENTRATIONS of fluoride in drinking water. Dental Abstracts, 21 (5) :276, May, 1976.

3. CORDERO. Ch. OIman, Remoción parcial de fluoruros del água potable. In:SIMPÓSIO SOBRE NUEVOS MÉTODOS DE TRATAMENTO DE AGUA, Asunción, 1972. Memorias. Lima, CEPIS, 1973. p.542.

4. CULP, Russell L. \& STOLTENBERG, Howard A. Fluoride reciuction at la Crosse Kan. Journal American Water Works Association, New York, 50(3) :423-31, Mar. 1958.

5. EULER, L. M: Washington Suburban Sanitary District. p. 280-2. (In: Fluoridation planning and operating experience: a symposium. Am. Water Works A.J., 45:275-88, Mar. 1953), apud: MACHADO, Oswaldo de Oliveira. Problemas de controle operacional. In:__. Classificação e apreciaçãodas objeções levantadas contra a fluoretação. São Paulo, Simpósio de Engenharia Sanitária, 1? D.A.E. Gov. do Est. de São Paulo, 18 a 30 de abril de 1968. p. 73.

6. HARRIS, W. L., Statement of p. 329-32 (In. U.S. Congress. Houve. Commitee on Interstate and Foreign Commerce. Fluoridation of Water. Hearings before the Commitee on Interstate and Foreign Commerce. Fluoridation of water. Hearings before the Commitee on Interstate and Foreign Commerce, House of Representatives, 83 rd Congress, 2nd ress, on H.R. 2341, a bill to protect the public from the dangers of fluoridation of water, May 25, 26 and 27; 1954. Washington, Government Printing Office, 1954. VI - 491 p.), apud: MACHADO, Oswaldo de Oliveira. Problemas de controle operacional. In:_. Classificação $e$ apreciação das objeções levantadas contra a fluoretação, São Paulo, Simpósio de Engenharia Sanitária, 19 D.A.E., Gov. do Est. de São Paulo, 18 a 30 de abril de 1968. p. 72.

7. HEYES, P. \& SHERU, R. Chemical adjuvents for control and prevention of dental plaque disease. Journal of American Society Preventive Den. tistry, 1:18-20, Jan-Fev. 1971.

8. MACHADO, Oswaldo de Oliveira. Problemas de controle operacional. In:_- Classificação e apreciação das objeçóes levantadas contra a fluoretação. São Paulo, Simpósio de Engenharia Sanitária, 1 0 D.A.E., Gov. do Est. de São Paulo, 18 a 30 de abril de 1968. p. 73.

9. MAIER, F. J. Control de la concentración de fluoruro: procedimiento de laboratório. In:_. Fluoruración del água potable, Washington, Organización Mundial de la Salud, 1971. cap. 10, p. 170-82 (Publicación Científica No 203). 
10. Fluoridation of a public water supplies: point of application. In:- . MC CLURE, F. J. Fluoride drinking waters, Bethesda, National Institute of Dental Research, 1962. p. 261-62.

11. História y desarrollo. In: _. Fluoruración del água potable, Washington, Oraganización Mundial de la Salud, 1971. cap. 1, p. 11-23 (Publicación Científica № 203).

12. _.__ . Objeciones técnicas (de ingeniería, qứmicos, industriales y económicas). In: _. Fluoruración del água potable. Washington, Organización Mundial de la Salud, 1971. cap. 4, p. 43.52 (Publicación Científica No. 203).

13. __. Tipos y capacidades de los dosificadores. In:_. Fluoruracion del água potable. Washington, Organización Mundial de la Salud, 1971. cap. 7, p. 99:127 (Publicación científica No 203).

14. Normas para a implantação de serviços de fluoretação das águas. (Porto Alegre, Comissão de Elaboração de Normas Técnicas de Fluoretação das Águas de Abastecimento Público, 1976) Polígrafo.

15. ORGANIZAÇÃO MUNDIAL DA SAÚDE. Organização Panamericana da Saúde. Análise de fluoreto na água pelos métodos SPADNS com destilação preliminar (direto, eletrodo especifico, Scott-Sanchis, Washington, OMS/OPS. 1975 (Documento HP/DH/32/P).

16. PERA, A. Tonzari. Técnica de abastecimento e tratamento de água. In:- Fluoretação das águas, São Paulo, Universidade de São Paulo. 1974. v. 2, cap. 28 , p. 987.96 .

17. PORTO ALEGRE. Departamento Municipal de Água e Esgotos. Grupo de avaliação da poluição do Guaiba. In:_. Manual para técnicos encarregados de plantas de tratamento de aguas. Porto Alegre, s.d. p. 221-22.

18. SANTOS, Flávio Belan dos. Contribuição ao ensino da odontologia social e preventiva; experiência de um programa extra-muros, Pelotas, s. ed., 1975. 65 p. Tese (Docente-Livre). Curso de Odontologia, Pelotas, 1975.

19. SOARES, Jair de Oliveira. Seminário sobre a prevenção da cárie dentária no Brasil. (Palestra proferida), Brasília, 9 de março de 1978.

20. SPITZ, Grace C. S., et alii. Experience in maintaining constant fluoride concentrations. In: - . MC CLURE, F. J. Fluoride Drinking Wa. ters. Bethesda, National Institute of Dental Research, 1962. p. 274.78.

21. STANDARD methods for the examination of water and wastewater: fluoride. In:_. Annual book of ASTM standards. Philadelphia, American Society for Testing and Materials, 1976. Part. 31, p. 309.13.

22. SUFELT, J.C., and SMITH, L. A. Experience with fluoridation of drinking water. Am. Water Works A.J., 42:839-48, Sept. 1950, apud: MA. CHADO, Oswaldo de Oliveira. Problemas de controle operacional. In:- Classificação e apreciação das objeções levantadas contra a fluoretação. São Paulo, Simpósio de Engenharia Sanitária, 10 D.A.E., Gov. do Est. de São Paulo, 18 a 30 de abril de 1968. p. $72 \cdot 73$.

23. TEIXEIRA, Alpha da Rosa. Aplicação da fluorita na fluoretação da água que abastece a cidade de Farroupilha, RS. In: _. Congresso Brasileiro de Engenharia Sanitária, 4‥ Brasília, julho, 1967. 